\title{
Bilateral Madelung Deformitesinde Düzeltici Osteotomi
}

\author{
Corrective Osteotomy for Bilateral Madelung's Deformity
}

\author{
Hasan Göçer, Sabit Numan Kuyubaşı, Alper Çıraklı \\ Ondokuz Mayıs Üniversitesi Tıp Fakültesi, Ortopedi ve Travmatoloji Anabilim Dalı, Samsun, Türkiye
}

\section{Özet}

Madelung deformitesi el bileğinin gelişimsel anomalisidir. Distal radius büyüme plağının medial tarafının gecikmiş büyüme hızına ve eklem yüzeyinin rotasyonu sonucunda radiusun medial bölümünün göreceli kısalması ve eklem yüzeyinin volar rotasyonuna bağlı olarak oluştuğu düşünülmektedir. Klinik ve radyolojik bulgular deformite için tanı koydurucudur. Hasta semptomlarının şiddetine bağlı olarak konservatif ya da cerrahi yöntemler ile tedavi edilir. Yazımızda bilateral Madelung deformitesi tanısı ile ameliyat edilen olguyu literatür eşliğinde sunduk. (Haseki Tıp Bülteni 2014; 52: 144-7)

Anahtar Sözcükler: Madelung deformitesi, el bileği ağrısı, düzeltici osteotomi

\section{Giriş}

Madelung deformitesi modern radyografi gelişinden önce 1878 ylında Madelung tarafından tanımlanmıştır (1). Madelung deformitesi distal radioulnar eklemi de ilgilendiren elin karakteristik anterior subluksasyonu ile sonuçlanan radiusun ilerleyici eğriliği olarak tanımlanmıştır (2). Erkek hasta ile karşılaştırıldığında kadın hastalarda 3-5:1 oranında daha sık ve genelde bilateral görülür (3). Deformite klinik olarak 6 ile 13 yaş arasında ortaya çıkmaktadır. Madelung deformitesi etyolojik faktörlere göre travma sonrası, displastik, genetik ve idiopatik nedenler olarak genellikle 4 gruba ayrılır (3). Klinik bulgular tipik olarak adölesan dönemde ağrı, eklem hareketlerinde azalma ve kozmetik sorunlar şeklinde ortaya çıkar $(4,5)$. Genelde tanı için direkt grafiler yeterlidir. Distal radius, ulna ve karpal kemik anormallikleri görülür (6). Semptomların göreceli şiddetine bağlı olarak konservatif veya cerrahi yöntemlerle tedavi edilir (7).

\begin{abstract}
Madelung's deformity is the developmental anomaly of the wrist. Delayed growth rate of the medial side of the distal radius growth plate and articular surface rotation causing relatively shortening of the medial side of the radius are considered to be the main reasons. The diagnosis of the condition is based on clinical and radiological findings. Patients with this deformity are treated by surgical or conservative methods according to the severity of the symptoms. In this paper, we present a patient with bilateral Madelung's deformity who underwent corrective osteotomy. (The Medical Bulletin of Haseki 2014; 52: 144-7)
\end{abstract}

Key Words: Madelung's deformity, wrist pain, corrective osteotomy

\section{Olgu}

On üç yaşında bayan hasta her iki el bileğinde şekil bozukluğu, hareket kısıtlılı̆ı ve ağrı şikayeti ile polikliniğimize başvurdu. Üst ekstremitede her iki kolda kısalık, el bileği rotasyonu ve el bileği volar dorsal fleksiyonunda kısıtlılık tesbit edildi. Yapılan radyolojik görüntülemede her iki radius distalde kısalık, volar ve mediale açılanma, ulnada göreceli uzunluk ve dorsalde belirginleşme tesbit edildi (Resim 1). Kozmetik sorunlar ve klinik şikayetleri nedeniyle iki seansta cerrahi olarak radius distaline düzeltici dome osteotomi ile tedavi edilmesine karar verildi.

Genel anestezi ve pnömotik turnike altında el bileğine distal volar insizyonla girildi. Radius distal eklem yüzeyi ortaya konuldu. Radius distal medialde hipertrofik fibrotik radioulnar volar ligamenti bulunup kesildi. Epifiz çevresi serbestleştirildi. Skopi eşliğinde frontal ve aksiyel planda eklem yüzeyine paralel iki adet krischner teli (KT) yerleştirildi. Planlanan osteotomi hattının proksimalinde de aksiyel ve frontal planda diafize dik iki adet KT yerleştirildi. 
Radius distal medialden laterale doğru eklem yüzeyine iki plandada rotasyonel dome osteotomi yapıldı. Daha önce yerleştirilen distal radius kısmı KT'leri kullanılarak skopi eşliğinde ideal radial ve dorsal inklinasyon elde edilecek şekilde eklem yüzeyi oluşturuldu. Üç adet KT ile tesbit edildi (Resim 2). Skopide kontrol edilerek katlar anatomisine uygun kapatıldı. Kısa kol sirküler alçı yapıldı. On beş gün sonra sütürler alındı ve dört hafta sonunda alçı çıkarıldı. Aktif ve pasif hareket başlandı. Altı hafta sonunda KT'ler çıkarıldı.

Bulgular; el bileği volar fleksiyon açısı ameliyat öncesi ve sonrası $90^{\circ}$ olarak korunurken dorsal fleksiyonun $10^{\circ}$ 'den $50^{\circ}$ ye arttığı görüldü. Tedavi öncesi el bileğinde mevcut olan ulnar deviasyon ve ulna stiloid şişliği, ameliyat sonrasında el bileği nötralde olacak şekilde ulna stiloid belirginliği kayboldu (Resim 3). Ameliyat öncesi ortalama radial eğim $57^{\circ}$ iken ameliyat sonrası birinci yılında $24^{\circ \prime}$ ye düştüğü görüldü. Ameliyat öncesi ortalama radius volar

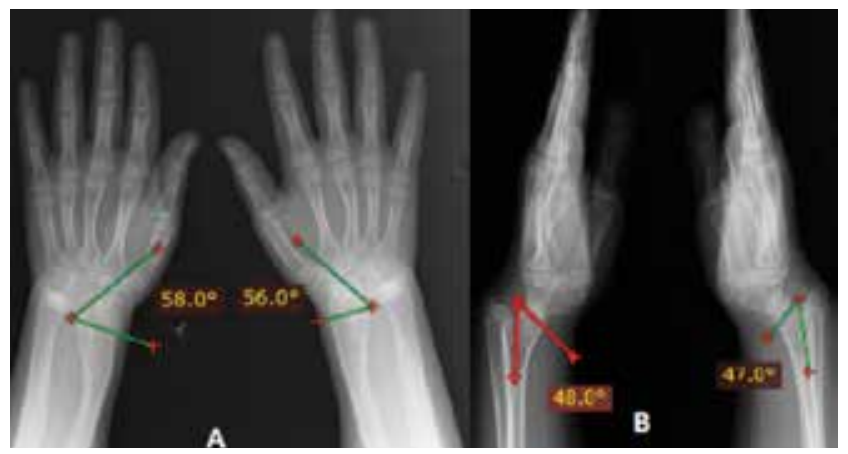

Şekil 1. Her iki el bileği A. Ön-arka B. Yan direkt grafisi

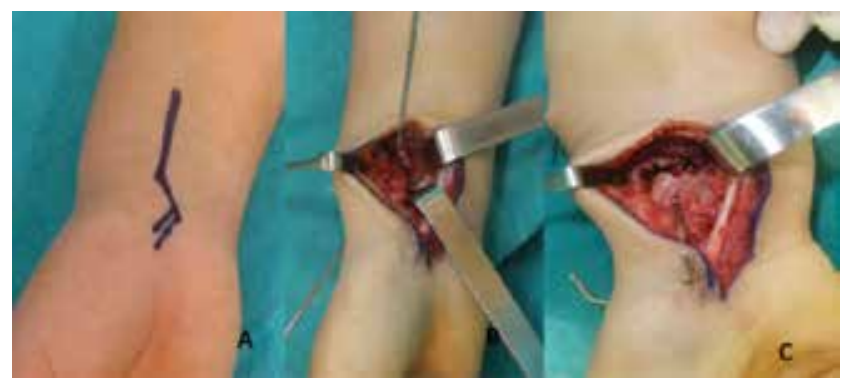

Şekil 2. El bileği intraoperatif görünümü. A. Insizyon hattı B. Eklem yüzeyine paralel gönderilmiş iki adet klavuz krischner teli C. Osteotomi ve tel ile tesbit sonrası görünümü inklinasyon açısı $47^{\circ}$ iken, sonrasında $2^{\circ}$ ye düştüğü gözlendi (Resim 4). Postoperatif bir yıl sonundaki el bileği radial eğim, radial volar inklinasyon açıları ameliyat öncesi ve sonrası değerler tabloda verilmiştir (Tablo 1).

\section{Tartışma}

Madelung deformitesi distal radioulnar ve radiokarpal eklemin ilerleyici deformitelerini içerir (2). Genel nüfusun \%2'sinden azında, erkek hasta ile karşılaştırıldığında kadın hastalarda 3-5:1 oranında daha sık görülür (3). Tipik olarak bilateraldir ve nadiren 7 yaşından önce ortaya çıkar (3). Bazı yazarlar deformitenin orta veya geç ergen dönemde görülmesini, adölesan büyüme atağı ile bağlantıı olabileceğini düşünmektedir (1).

Hastalığın etyolojisi kesin olarak bilinmemekle beraber tüm varsayımlar distal ve volar radyoulnar kısmın epifiz plaklarında büyüme bozukluğunun neden olduğu yönündedir (8). Madelung deformitesi etyolojik faktörlere göre travma sonrası, displastik, genetik ve idiopatik

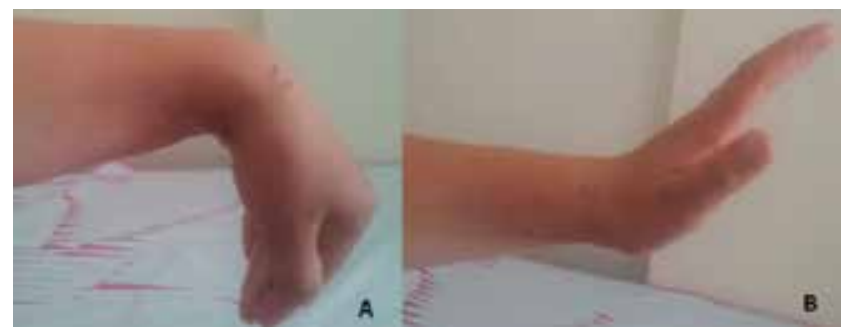

Şekil 3. Ameliyat sonrası el bileği fonksiyonel görünümü A. Volar fleksiyon B. Dorsal fleksiyon

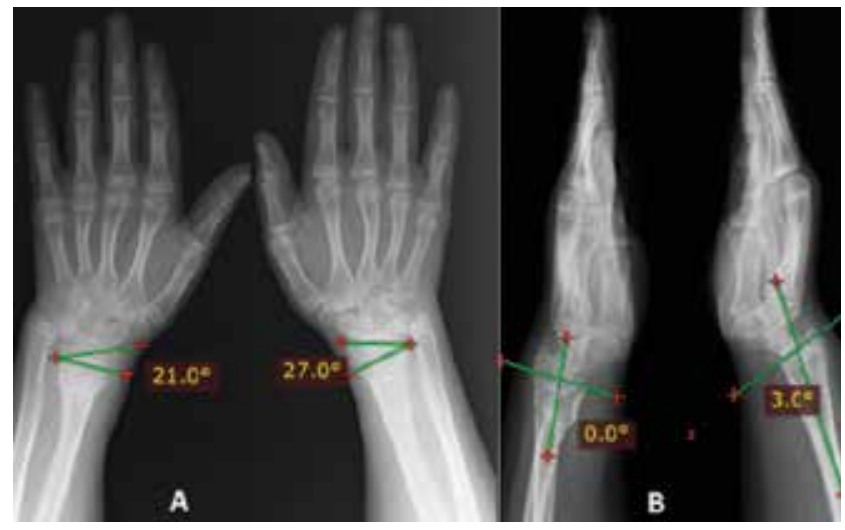

Şekil 4. Her iki el bileğinin bir yıl sonundaki ön-arka ve yan direkt grafisi görülmekte

\begin{tabular}{|l|l|l|l|l|c|}
\hline \multicolumn{2}{|c|}{ Tablo 1. Her iki elbileği ameliyat öncesi ve bir yıl sonraki direkt grafide ölçülen radius distal açı değerleri } \\
\hline & Sağ elbileği & Sol elbileği & Normal sınırlar \\
\hline & Preop & Postop & Preop & postop & \\
\hline Radial eğim & $58^{\circ}$ & $21^{\circ}$ & $56^{\circ}$ & $27^{\circ}$ & $16^{\circ}-28^{\circ}$ \\
\hline Radial volar inklinasyon & $48^{\circ}$ & $0^{\circ}$ & $47^{\circ}$ & $3^{\circ}$ & $0^{\circ}-22^{\circ}$ \\
\hline
\end{tabular}


nedenler olarak genellikle 4 gruba ayrılır $(1,3)$. Genetik Madelung deformitesi klinik olarak Turner sendromu ile bağlantılı olmakla beraber diğer genetik bozukluklarda eşlik edebilir (9).

Travma sonrası gelişen deformite tipik el bileğinin aşırı ve/veya kötüye kullanımı ile uzun zaman içinde gelişir (10). Displastik Madelung deformitesi mezomelik cücelik şeklidir ve genellikle kısa ön kol ve bacaklar eşlik eder (3). Genetik, travmatik ve displastik tiplerden herhangi birine girmeyenler idiyopatik tipte toplanmaktadır.

Olgumuz 13 yaşında kız hasta olup şikayetleri yaklaşık son iki yıldır artmaya başlamaştır. Her iki ön kolda ve alt ekstremitede kısalık olması, ek başka anomali olmaması ve travma öyküsü yokluğu nedeniyle displastik gruba girmektedir. Ağrı şikayetinin artması günlük basit intiyaçlarını karşılamaktaki sorunları, bayan olması ve kozmetik olarak el bileğinin görünümünden rahatsız olması nedeniyle cerrahi olarak tedavi etmeyi planladık.

Madelung deformitesinde klinik bulgular tipik olarak adölesan dönemde ağrı veya eklem hareket açıklığının sınırlanması şeklinde ortaya çıkar. Ağrı, akut bir travmatik epizodla ya da kronik mikrotravma ile tetiklenebilir (4). El bileği ekstansiyonu ve supinasyonu azalmış bulunabilir. Distal ulna dorsale disloke olur ve redükte edilebilir. Radyolojik değişiklikler çok belirgin olmasına rağmen, pek çok hastada ciddi fonksiyonel ve kozmetik bozukluğa neden olmayabilir (5).

Olgumuzun el bileklerinde dorsal hareket ve supinasyonda kısıtlık mevcut olup ulnar stiloidde belirgin yükseklik ve şişlik mevcuttu.

Madelung deformitesinde radyolojik bulgular tanı koydurucudur. Radius distal, ulna distal ve karpal anormallikler şeklinde toplanabilir. Radius distalde volar inklinasyon ve radial eğim artmış, radius uzunluğu, distal radial epifizin eşit olmayan büyümesi ile birlikte radial epifizin medial yarııının erken kapanması nedeniyle kısalık gelişir. Ulna distalde dorsal subluksasyon, başın genişlemesi ve uzunlukta değişiklikler görülür. Radius ve ulna ile karpal kemikler arasında kamalaşma ve triangular konfigürasyon eşlik edebilir (6).

Olgumuzda radius distal medial ve volarde gelişme geriliği nedeniyle radial eğim sağda $58^{\circ}$, volar inklinasyon $48^{\circ}$ olarak ölçülürken, solda sırasıyla $56^{\circ}$ ve $47^{\circ}$ olarak ölçüldü (Tablo 1). Radiokarpal eklemlerde uyumsuzluk, ulna stiloidde dorsalde belirginleşme ve radiusa göre daha hafif uzun olduğu görüldü.

Madelung deformitesi genellikle semptomların şiddetine bağlı olarak konservatif ya da cerrahi yöntemlerle tedavi edilir (7). Cerrahi tedavi el bileğindeki bir dizi problemi düzeltmek için geliştirilmiştir (7). Cerrahi tedavi ergen ve genç erişkinlerde ağı ve kozmetik rahatsızlığın ileri olduğu hastalarda tercih edilir $(1,7)$. Cerrahi teknikler önemli ölçüde farklılık gösterse de 3 grupta toplanabilir.
Birinci grup tek başına radiusa uygulanan epifizyodez, düzeltici osteotomi ve fizyoliz tekniklerini içerir (8). íkinci grup epifizyodez, ulna distal eksizyonu veya kısaltma osteotomisi yapmaktır (11). Üçüncü grup bu tekniklerin bir kombinasyonunu içerir.

Brooks ve ark. 21 yaşında bir hastaya uyguladıkları radius distal uç düzeltici osteotomi sonrası ağrıda azalma, gelişmiş hareket aralığının ve kavrama kuvvetinde artışın önemli düzeyde olduğunu göstermiştir (12). Başka bir çalışmada konservatif tedaviden tatmin edici sonuç alamayan 18 hastadan 9'una ağrı nedeniyle cerrahi tedavi uygulanmış. Bu 9 hastanın 2'sinde cerrahi sonrası ağrının devam ettiği, geriye kalan 7 hastada ağrı düzeyinde önemli ölçüde düşüş olduğu bildirilmiştir. Ayrıca hastaların el bileği hareketi ve kavrama gücü konusunda istatistiksel olarak anlamlı bir düzelme olduğu belirtilmiştir (10). Vickers ve Nielsen 17 cerrahi uygulanan hastada cerrahi kriter olarak 14'ünde ağrı, 3'ünde kozmetik nedenler gösterilmiş. Ağrı şikayeti olan tüm hastalar cerrahi sonrası ilk 6 ay içinde önemli bir rahatlama yaşamıs, sadece 4 hastanın el bileğindeki ağrı tamamen kontrol altına alınabilmiş. Fakat tüm hastalarda özellikle supinasyon olmak üzere tüm eklem hareket açıklığında anlamlı artma elde edilmiş. Anormal radioulnar volar bag rezeke edilmiş ve radius osteotomisi yapılan 26 immatur el bileğinde ulnar taraf ağrısının ulnar kısaltma ile azaltıldığı gösterilmiş ancak bu işlem sonrası eklem hareket açıklığı önemli ölçüde geliştirilememiş. Bu basit prosedürün izole ulnar taraf şikayeti olan hafif düzey Madelung deformiteli olgular için uygun olabileceğini göstermişler (13). Ranavat ve ark. ameliyat yaptıkları 13 hastanın 7'sine darrach prosedürü, 1 'ine ulnar kısaltma ve 5 'ine de darach prosedürü ile birlikte biplanar radial osteotomi uygulamış. Hastaların el bileği ağrılarında azalma, kavrama gücünde artış olmasına rağmen hareket aralığında önemli değişiklik olmamış ve izole ulnar taraf cerrahisi yapılan hastalarda daha fazla dejeneratif değişiklik ve karpal subluksasyon meydana gelmiş. İzole ulnar taraf cerrahisinin anormal radyokarpal ilişkiyi gideremediğini, distal radius osteotomisi ile el bileğine daha normal biyomekanik fonksiyon kazandırıldığı belirtilmiş (14).

Olgumuzda her iki el bileğinde klinik şikayetlerde, elin kavrama kapasitesinde belirgin iyileşme ve görsel olarak da deformitede gerileme elde edildi. Radyolojik olarak ameliyat öncesi ortalama radial eğimin $57^{\circ}$ den $24^{\circ \prime}$ ye, volar inklinasyon açısının ise $47^{\circ}$ den $2^{\circ \prime}$ ye düştüğü görüldü. Radyolojik olarak ve fonksiyonel olarak belirgin iyileşme sağlandı. Bir yıl sonundaki kontrolde el bileği hareketlerinde kısıtlı iyileşme görülürken, radyolojik olarak eklem yüzeyinin restore edildiği, osteotomi hattının kaynadığı, daha fonksiyonel, ağrısız ve kavrama gücü fazla olan bir el bileği elde edilmiş oldu (Resim 3). 
Sonuç olarak Madelung deformitesine bağı radius alt uç deformiteleri, özellikle ağrı ve kozmetik sorun olması halinde cerrahi olarak tedavi edilebilir. Radius distal dome osteotomi ile osteotomi hattının distalinde kalan parça her eksende manipüle edilerek istenilen ideal düzeltme elde edilebilceğini düşünmekteyiz.

\section{Kaynaklar}

1. Vickers D, Nielsen G. Madelung deformity: Surgical prophylaxis (physiolysis) during the late growth period by resection of the dyschondrosteosis lesion. J Hand Surg Br 1992;17:401-7.

2. Vender MI, Watson HK. Acquired Madelung-like deformity in a gymnast. J Hand Surg Am 1988;13:19-21.

3. Casford B. Madelung's deformity. Available at: http:// brighmrad.harvard.edu/Cases/mcr/hcache/205/full.html. Accessed April 19, 2000.

4. Schwartz RP, Sumner TE. Madelung's deformity as a presenting sign of Turner's syndrome. J Pediatr 2000;136:563.

5. Ünsal S, Kaya K, Özel S. Fiziksel Tıp 2002;5(1):47-9.

6. Resnick D. Additional Congenital or Heritable Anomalies and Syndromes. In: Resnick D, editor. Bone and Joint Imaging. Philadelphia, W.B. Saunders Company; 1996. p. 1167-87.
7. Lamb D. Madelung deformity. J Hand Surg Br 1988;13:3-4.

8. Brashear HR, Raney RB. Handbook of Orthopaedic Surgery. 10th ed. St Louis, MO: CV Mosby Co; 1986. p. 496-7.

9. UW Radiology Main Online Teaching File. Roentgenographic abnormalities in Madelung's deformity. Available at: http:// www.rad.washington.edu/maintf/cases/unk53/answers. html. Accessed April 19, 2000.

10. Watson HK, Ryu JY, Burgess RC. Matched distal ulnar resection. J Hand Surg Am 1986;11:812-7.

11. Brooks TJ. Madelung Deformity in a Collegiate Gymnast: A Case Report. J Athl Train 2001;36:170-3.

12. Mandelbaum BR, Bartolozzi AR, Davis CA, Teurlings L, Bragonier B. Wrist pain syndrome in the gymnast: pathogenetic, diagnostic, and therapeutic considerations. Am J Sports Med 1989;17:305-17.

13. Harley BJ, Brown C, Cummings K, Carter PR, Ezaki M. Volar ligament release and distal radius dome osteotomy for correction of Madelung's deformity. J Hand Surg Am 2006;31:1499-506.

14. Ranawat CS, Defiore J, Straub LR. Madelung' s deformity: an end result study of surgical treatment. J Bone Joint Surg Am 1975;57:772-5. 